\title{
The internal and external challenges facing clients in implementing IMC
}

\section{Abstract}

Purpose

Although IMC is generally accepted as the way forward by academics and practitioners, there is a shortage of research into the challenges that clients face in implementing the process, particularly in the UK. This study addresses these issues by examining how UK clients perceive the barriers to implementation, with reference to the conflict theory of decision making and the social exchange theory from the change management literature.

Design/methodology/approach

The study adopted a critical realism approach and collected data through an on-line questionnaire to an expert panel of UK clients, which generated some rich qualitative data. The experts were asked to comment on four statements developed from the literature which captured the main challenges identified in previous research.

Findings

The results indicate that UK clients are facing similar barriers to those evident in other countries more than a decade ago. Three main obstacles are identified. Firstly, some clients still find IMC difficult to understand and therefore may avoid change because of the high level of risk involved. Secondly, marketing departments lack control or influence over other parts of the organisation, due in some cases to lack of representation at board level. Lastly, agencies do not have a clear role in the implementation of IMC.

Originality/value The paper is of value because it looks specifically at the UK client perspective, which is presently sparse in the literature and updates our knowledge on barriers to implementation. It underpins this discussion with reference to change management theories. The paper also examines the support being provided by industry bodies and questions their effectiveness. 


\section{Background}

There is now acceptance by many academics and practitioners that Integrated Marketing Communication (IMC) is the way forward in this complex multi-platform digital environment in which we now operate. Kerr and Patti (2013) recently referred to its development as being in its mid-range level of maturity. This position has been reached as a result of discussions and debates in the literature where a high degree of misunderstanding by many has been identified (Luck and Moffatt, 2009), where its usefulness and value has been questioned (Christensen et al., 2008; Kitchen et al., 2008) and where further work into definitions and measurements have been necessary (Schultz and Patti, 2009).

Kliatchko (2008), who provides an overview of the development of research from 1990 to 2006 , proposes that some agreement has been reached on definitions and justifications and that discussions have moved on to more specific areas such as the relationship between IMC and branding and the importance of internal marketing. He provides a definition which is built upon this developing knowledge and is referred to by much of the recent literature in the area (e.g. Reinold and Tropp, 2012; Johansen and Andersen, 2012). IMC is ...'an audience-driven business process of strategically managing stakeholders, content, channels, and results of brand communication programs' (Kliatchko, 2008, p. 140).

One of the main themes in the definition that has gained acceptance is that the process needs to be audience-driven or customer-centric. A customer-centric approach is achieved by adopting an outside-in approach and ensuring that all business practices have the customer in the centre. This is increasingly aided by the use of extensive databases that provide rich 'big' data on customer purchase behaviour as well as consumer insight through interaction and dialogue. The definition also states clearly that true integration takes place at a strategic level of an organisation and involves a number of different stakeholders. This is supported in a study by Laurie and Mortimer (2011) who found that communication agencies were beginning to acknowledge IMC as involving all departments and functions of an organisation, i.e. at a strategic level, which is an advancement from opinions voiced only a few years earlier (Kitchen et al., 2008) when IMC was mainly perceived by agencies to be 'Coordination of the various communication disciplines'. This strategic shift is seen as 
fundamental to the achievement of true integration and has been recognised by the small but significant linguistic change from Integrated Marketing Communications, with an " $s$ " which refers to the integration of different methods to Integrated Marketing Communication, which is a discipline or function (Luck and Moffett, 2009). However, it should be noted that some recent literature utilises new terminology to emphasise the strategic element of IMC which muddy the waters somewhat e.g., ICM: Integrated Communications Management (Einwiller and Boenigk, 2012), SIC: Strategic Integrated Communications (Barker, 2013), SI: Strategic integration (Kerr and Patti, 2013). Practitioners have also renamed IMC in various ways, mainly to differentiate themselves from competing agencies, and talk about post-integration, which can cause confusion (Laurie and Mortimer, 2011).

More evidence of the effectiveness of IMC in terms of business performance has been identified as necessary to convince both scholars and practitioners of its value (Ewing, 2009) and a body of support is building in this area. Einwiller and Boenigk, (2012) found a clear relationship between strategic integration and both hard and soft measures of communication effectiveness i.e. ROI, market share and customer satisfaction. More recently, Luxton et al., (2015) identified a direct relationship between IMC capability, campaign effectiveness and brand market performance leading to a positive brand financial performance. For this body of evidence to develop further some consensus on the best way of measuring IMC is necessary. Kliatchko (2008) suggests that the metrics of IMC should move towards the use of Return of Customer Investment (ROCI) as a holistic way of identifying the overall impact of IMC. Reinold and Tropp (2012) created a model of measuring IMC effectiveness which included both elements of brand touch points and brand content effectiveness. Kerr and Patti (2014) proposed a Strategic Integration management tool to assist organisations in measurement. Despite these developments there is recent evidence to suggest that many marketers are not formulating clear and measurable marketing communications objectives which is crucial if effectiveness of integrated campaigns is to be identified (Patti et al., 2015).

One of the main criticisms of IMC is that it is all about control and conformity and therefore it prevents companies from being flexible and adapting to changing circumstances 
(Christensen et al., 2008/2009). Kliatchko (2008) agrees that the approach needs to be flexible but argues that flexibility and consistency are both achievable through communication and co-ordination, including the sharing of information across the organisation. Mulhern (2009) supports the link between IMC and the use of behavioural data which can assist in strategic planning across multiple stakeholder groups.

However there is still one important part of the jigsaw puzzle missing which is that few client companies are adopting IMC fully despite the benefits of doing so (Kitchen and Burgmann, 2010; Luck and Moffatt, 2009). Making fundamental changes within any organisation can be difficult, particularly if the risk of it not being successful is high. Wright et al., (2004) refer to the conflict theory of decision making which proposes that managers choose from three different coping patterns when such decisions have to be made: Procrastination which is putting the decision off, shifting the responsibility on to someone else or choosing the least worst option which is often business as usual. All these routes tend to lead to inertia and nothing changes. The perceived level of risk in managing change can be reduced if control is maximised or if trust in fellow employees or in the organisation is high. These constructs are linked to the Social Exchange theory, borrowed from the Organisational Behaviour literature, which states that trust is a result of the exchange of benefits, or social exchanges, which is a sign of mutual support (Cropanzano and Mitchell, 2005). This involvement and understanding should lead to trust in the organisation which makes change easier to implement. This trust is particularly important if the level of control over employees' behaviour is low and it can lead to an improved level of confidence in management. Indeed, Das and Teng (1998) propose that control may not be necessary when there is full trust. This is relevant to IMC because employees are identified as key stakeholders in implementing the process at all levels of the organisation, where the marketing department may not have authority. Internal marketing has been recognised, therefore, as critical to minimise the perceived level of risk and to create support and trust (Kliatchko, 2008).

It is important to identify the main barriers to the implementation of IMC from the client perspective so that strategies can be put in place to dismantle them. This insight into the client viewpoint is presently lacking in both the academic and practitioner literature. Kitchen 
and Burgmann (2010) acknowledge that 'as most IMC research has been conducted with regard to advertising agencies, little is known about actual IMC application within client firms' (p. 7). Kitchen and Schultz (2009) also suggest that too many studies have examined the role of the communication agency in the implementation of IMC while it is now accepted that the client businesses are the prime movers. The research that does exist on the client perception is fragmented, spanning thirty years and a number of different countries including New Zealand (Eagle and Kitchen, 2000) Sweden (Holm, 2006), USA (Duncan and Everett, 1993; Pettegrew, 2000/2001), Australia (Ewing et al., 2000) and AsiaPacific region (Kliatchko and Schultz, 2014). A study, however, has not yet been undertaken in the UK, which is surprising when one considers the important role that UK plays in the global advertising industry. A total of $£ 16$ billion is spent on advertising in the UK annually, creating over $£ 2$ billion in the exporting of advertising services so it is a key market to investigate (Advertising Association, 2015). This paper therefore contributes by exploring the challenges that UK clients are facing today, as they operate in this turbulent media landscape.

The following discussion on barriers to the implementation of IMC will encompass both the views of agencies and clients to enable a comparison to be made before examining the views of clients specifically to aid our understanding in this area.

\section{Barriers to the implementation of IMC}

A number of barriers to the implementation of IMC have been suggested in the literature from as early as 1993 (Duncan and Everett, 1993) and four main obstacles have been identified. The first is a lack of understanding of IMC within the client organisations. Eagle and Kitchen (2000), based in New Zealand, found that clients considered their staff to be ill equipped to manage an IMC programme and needed to develop new skills and expertise to work in this integrated manner. It was felt that existing marketing communications educational programmes concentrated too much on the tools available and needed to view communications from a broader business perspective. Holm (2006), who studied four large 
Swedish organisations, also concluded that the subjects taught to people involved with communications at a tactical level were quite different from those taught to staff operating at a strategy level and consequently it was difficult for these two groups of people to find common ground. Lack of client knowledge of IMC has also been identified by agency executives as a problem (Kitchen and Schulz, 1999). Clients have been found to be reluctant to change working habits and responsibilities when faced with the perceived complexity of planning and coordination that IMC requires, leading to inertia, and this may be because client organisations find the concept difficult to understand (Fill, 2013; Luck and Moffatt, 2009). Consequently, in order to avoid conflict, they may make small alternations instead of taking the time to implement comprehensive change, leading to disappointing results and disillusionment.

The second identified barrier is existing organisational structures and frameworks and opposition to changing them. Many large client organisations have a traditional structure with departments arranged around functional specialisms. These departments have differing goals, which are often short-term and require separate budgets. Such a structure can prevent integration and the sharing of ideas across disciplines (Fill, 2013). A recent UK industry survey found that organisations that suffered from internal political barriers were weaker across a number of integration measures e.g. brand experience, consolidated of customer data (Econsultancy, 2013). Agency executives have also identified inappropriate organisational structures as a problem when working on IMC campaigns with their clients (Kitchen and Schulz, 1999). However changing these traditional structures is a significant challenge. Eagle and Kitchen (2000) found that internal staff perceived any changes to the existing structure as being a threat to their control (e.g. turf wars), and their budgets, and consequently there was considerable reluctance. It was therefore felt important to stress the need for 'liaison' between departments to address that perception. Some clients, in the same study, suggested that this 'liaison' needed to be controlled by a champion within the organisation, which is identified as the third barrier.

These barriers of organisational structures and lack of understanding may be easier to overcome if there is an IMC champion at a high enough level within the organisation with the authority and determination to make it work. Pettegrew (2000/2001) suggests that one 
of the fundamental barriers to implementation is often the absence of the support of the CEO because, without his or her support, integration does not take place at an appropriate level to influence the whole organisation. This is supported by Einwiller and Boenigk (2012) who found that leadership support and strategic integration led to increased communication effectiveness, both internally and externally. Kliatchko and Schultz (2014) state that "IMC issues have become 'C-suite' challenges" (p. 2) a term used to refer to an organisation's most senior executives. This lack of a voice at board level is therefore identified as the third key barrier. With the CEO support, challenges such as changing existing organisational structures and corporate cultural issues can be addressed.

Madhavaram et al. (2005) examined the relationship between IMC and brand strategy and concluded that top management support was necessary to create a brand identity-oriented culture. IMC has also been identified as a possible managerial framework for corporate branding (Biraghi and Gambetti, 2013) and corporate marketing (Johansen and Andersen, 2012). This again indicates the importance of its acceptance at both a tactical and a strategic level.

Swain (2004) supported Pettegrew (2000/2001) in identifying the leadership role as being an essential element in IMC implementation which had been overlooked. He examined who should take this leadership or 'champion' role within the client organisation by asking the opinion of academics, agency staff and clients in the US. The results indicated that the clients considered marketing managers to be the best initiators while agencies thought top management should take on that role which is an interesting distinction demonstrating that the agencies identified the importance of the 'C-suite' more than the clients. The results indicate that there is no general consensus on this issue.

This discrepancy between clients and agencies highlights the fourth key barrier to implementation which is the client-agency relationship. Kitchen et al. (2004) found that agencies were reluctant to adopt an integrated approach unless it was a requirement of their clients and it was therefore necessary for the client organisations to become integrated themselves. Four years later, in a follow-up study, results indicated that agency executives were able to create strategic campaigns but were still dependent on being given that responsibility by their clients (Kitchen et al., 2008). Further support for this view was 
provided by an IPA industry report (IPA, 2006) entitled 'Magic and Logic'. This report concludes that both clients and agencies have joint responsibility to adapt to the changing environment but that agencies cannot develop as quickly if clients are not adopting best practice.

However, IMC not only demands an integrative approach within the client organisation but also requires agencies to work together more closely for the benefit of the client. Ewing et al. (2000) found that clients consider agency politics as being one of the main barriers to IMC implementation, as agencies of different disciplines e.g. Advertising, Public Relations, may not always operate in the best interests of their clients. This debate is linked to how clients manage integrated campaigns and whether they use a lead agency to organise other agencies or organise them themselves. An IPA guide entitled 'Agencies Working Better Together' states that $80 \%$ of clients use either the All Agency model i.e. organise collaboration of agencies themselves or the Lead Agency model where one agency takes responsibility for integration across all the agencies. The IPA (2010) study found that the former model was popular with large organisations that had the manpower to adopt that role. Either way, Child (2012) found that clients often felt let down due to lack of cooperation and collaboration across different agencies. This argument was rebutted, in the same study, by agencies, who stated that clients wanted competitive pitches between agencies at the same time as requesting cooperation between them, making integration across agencies very difficult. Both sides agreed that more trust and respect was needed for this relationship to work.

\section{Methodology}

The purpose of this study was to examine the understanding that UK client organisations had of IMC and the barriers that they perceived to exist when implementing a more IMC approach in their organisations. The philosophical position being taken in this research was one of realism, in particular, critical realism which acknowledges that reality is socially constructed but there is also an element which is independent of the observer (Easton, 2010). Indeed, Sayer (1992, cited by Easton, 2010) proposed that this invariance is necessary 
if any theory is to be built. Critical realism is considered a fairly new orientation which is gaining popularity across the social sciences, including Business and more specifically Marketing (Ryan et al., 2012). Its popularity is down in part to its ability to provide rigour to studies with small sample sizes and to explain causal powers held by individuals and social structures through the use of certain mechanisms without the need to quantify effects (Peters et al., 2013). This philosophical position therefore seemed more appropriate than a pure constructivist approach where reality is considered to be entirely socially constructed preventing any opportunity to build theory or attempt to explain causality. Such an approach is relevant because the purpose of the study was to capture the views of a specific group of people who, because of their managerial position, had an understanding of and influence over the implementation of marketing communications and were able to appreciate the challenges of doing so. These understandings and perceptions were obviously very subjective and influenced by their own background and experiences. In order to capture these views a mono method approach was adopted. Although some quantitative data was collected its purpose was to identify patterns and provide internal generalisation within the group of individuals being studied. Maxwell (2010) refers to such use of data as quasi statistics and argues that their inclusion in the presentation of evidence does not necessarily mean that a study is mixed methods.

The data was collected through the use of an on-line questionnaire. Busy marketing managers and directors are obviously a difficult group of people to reach and so it was important to use an instrument that was reasonably accessible and convenient to them. The link to the questionnaire, which was created using the Bristol Online Survey software, was distributed to individuals who had knowledge and experience of IMC in two ways. Firstly, existing contacts of marketing managers were utilised and they were encouraged to pass on the link to other colleagues with an interest in the subject, thereby adopting a purposive and snowballing sampling method. The link was also kindly published in Campaign magazine, the leading UK advertising industry publication in their special supplement 'What next in Integration'.

Twenty three clients took part in the discussion, a number which compares favourably with other studies in this area (e.g. Swain, 2004; Eagle and Kitchen, 2000). Only two out of the 23 
participants identified themselves at being at 'entry level' of the organisation. The rest of the participants saw themselves in the categories of middle or senior management, board level or owner. This was important as the role of senior management, or the C-suite, was identified in the literature as being where a strategic IMC approach was being implemented. We were therefore satisfied that we were reaching people who not only had an opinion on IMC but also an influence on how Marketing Communications was undertaken in their organisation.

Table 1: Profile of participants in study

\begin{tabular}{|c|c|c|c|c|}
\hline $\begin{array}{l}\text { Level of } \\
\text { Management }\end{array}$ & $\begin{array}{l}\text { No of } \\
\text { respondents }\end{array}$ & Job Title & Sector & $\begin{array}{l}\text { No of } \\
\text { employees }\end{array}$ \\
\hline Owner & 1 & Director & B 2 B & $0-10$ \\
\hline $\begin{array}{l}\text { Director or } \\
\text { Board } \\
\text { Member }\end{array}$ & 4 & $\begin{array}{l}\text { Director } \\
\text { Communication } \\
\text { Director } \\
\text { Retail Marketing } \\
\text { Director } \\
\text { Consultant }\end{array}$ & $\begin{array}{l}\text { Financial (1) } \\
\text { Manufacturing (1) } \\
\text { Not for Profit (1) } \\
\text { Management } \\
\text { Consultant(1) }\end{array}$ & $\begin{array}{l}0-10(1) \\
11-50(1) \\
51-250(1) \\
>250(1)\end{array}$ \\
\hline $\begin{array}{l}\text { Senior } \\
\text { Management }\end{array}$ & 10 & $\begin{array}{l}\text { Head of Marketing } \\
\text { Communication } \\
\text { Manager } \\
\text { Head of Marketing } \\
\text { Project Leader Global } \\
\text { Brand \& Marketing } \\
\text { Consumer Insight } \\
\text { Advertising Manager } \\
\text { Marketing Director } \\
\text { VP Marketing } \\
\text { communications } \\
\text { Senior Director \& } \\
\text { Intelligence EMEA } \\
\text { SVP }\end{array}$ & $\begin{array}{l}\text { B } 2 \text { B (2) } \\
\text { Manufacturing (7) } \\
\text { Not for Profit (1) }\end{array}$ & $\begin{array}{l}51-250(1) \\
>250(9)\end{array}$ \\
\hline $\begin{array}{l}\text { Middle } \\
\text { Management }\end{array}$ & 6 & $\begin{array}{l}\text { Marketing Manager } \\
\text { Regional Marketing } \\
\text { Director } \\
\text { VP Business Unit } \\
\text { Consumer Activation } \\
\text { Manager } \\
\text { Communication } \\
\text { Manager } \\
\text { Marketing Executive }\end{array}$ & $\begin{array}{l}\text { B } 2 \text { B (1) } \\
\text { Manufacturing (4) } \\
\text { Retail (1) }\end{array}$ & $\begin{array}{l}51-250(1) \\
>250(5)\end{array}$ \\
\hline
\end{tabular}




\begin{tabular}{|l|l|l|l|l|}
\hline Entry Level & 2 & $\begin{array}{l}\text { Marketing Analyst/ } \\
\text { Communication Project } \\
\text { Leader }\end{array}$ & $\begin{array}{l}\text { B 2 B (1) } \\
\text { Transport (1) }\end{array}$ & $>250(2)$ \\
\hline
\end{tabular}

The participants were also asked to identify the size and type of organisation they worked for, using the Standard Industry Classification (SIC) codes. The details reveal a good crosssection of UK industry, with the majority working for companies with over 250 employees, and spread across manufacturing, business to business activities and services. As Table 1 indicates, they were a disparate group of people in terms of job title which is a reflection of the array of different titles that companies utilise for similar marketing positions. What is important for this study is that the participants were in a position to understand the challenges that clients face in maintaining consistent messages across multi-platforms and numerous stakeholders. To check their expertise and knowledge in marketing communications the participants were asked for their views on five descriptions of IMC. These five descriptions were taken from the work of Kitchen and colleagues on the views of practitioners on IMC (Kitchen et al., 2004/2008). The results, presented in Table 2, confirmed their understanding of it being about coordination and unification of different types of marketing communication messages to consumers with most clients linking it closely with brand strategy but more reluctant to suggest it has a great influence on the business overall. This feedback was in line with previous studies (Kitchen et al., 2008; Laurie and Mortimer, 2011) and provided confirmation that the participants had appropriate knowledge and experience.

Table 2: Confirmation of IMC understanding 


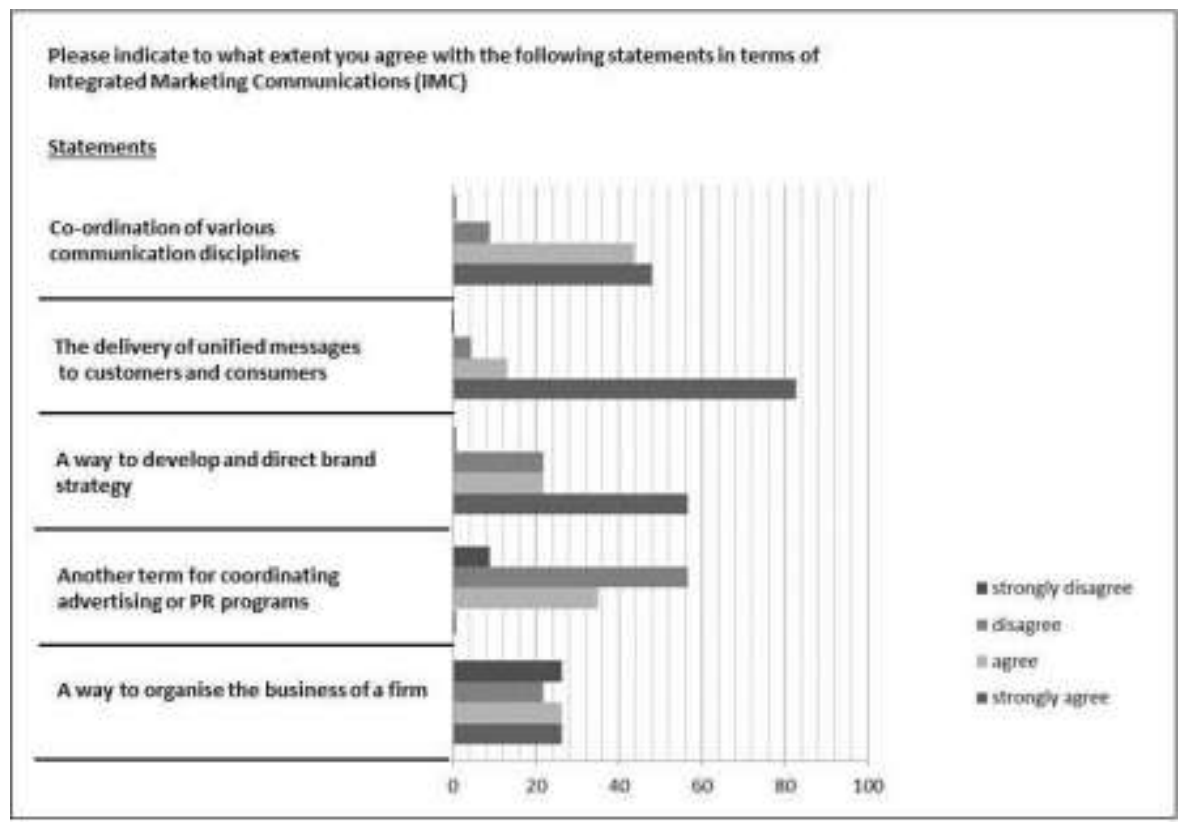

The participants were provided with four statements which were created to encapsulate a particular viewpoint that had been reported and discussed in the academic literature on the four main barriers to implementation i.e. lack of understanding, changing existing organisational structures, the need for a strategic approach with C-suite support, and the challenges of working with agencies. These statements were tested in a pilot study beforehand on four prominent members of the marketing communications industry, two on the client side of the business and two agency representatives. It was felt that this number was sufficient to identify any issues without reducing our pool of possible participants in the final study too drastically. The statements were sent by email individually with a request for them to undertake the pilot study and also provide feedback on the process. The comments received suggested that the statements and the process were straightforward and easy to understand. One participant did state that he felt some of the comments were rather controversial. After discussion, it was felt that some element of controversy may encourage participants to air their views and therefore no changes to the statements were made. These four statements were then sent out in the main study where participants were asked to agree or disagree with each statement and then explain their response. This provided the study with an overview of opinions, although obviously the numbers are small, and rich qualitative data was obtained.

The four statements are as follows: 
S1: Client organisations find the concept of IMC difficult to understand. Instead of implementing fundamental changes they undertake small-scale adjustments which can provide disappointing results and lead to disillusionment.

The first statement explores the suggestion that there is a perceived lack of understanding of IMC within client organisations which leads clients to resist making substantial changes to such things as organisational structures and budget allocations (Luck and Moffatt, 2009) due to the high level of risk (Wright et al., 2004).

S2: The agency and the client's marketing department often do not have influence over the rest of the brand's organisation and this can be a barrier to full strategic integration

The second statement addresses the issue of existing structures, turf wars and the lack of influence and control that marketing departments and their agencies have within their organisations (Fill, 2013).

S3: Full integration is only possible if IMC is perceived as a strategic tool and implemented at a senior level right across the client organisation, incorporating all departments, such as Finance and Human Resources, and all internal and external stakeholders.

The third statement examines the importance of support at board level as well as exploring the clients' understanding and perception of IMC as a strategic tool (Kliatchko and Schultz, 2014).

S4: Agencies are keen to implement an IMC approach but the initiative has to come from the client. If the client is integrated then the agency is in a position to be allocated tasks to reach IMC objectives.

Lastly, the fourth statement examines the perceived responsibility for implementing IMC and the relationship between the client and the agency (Kitchen et al., 2008). 
The statements were designed to encourage clients to provide qualitative feedback as well as a dichotomous answer and were successful in achieving that goal. Their comments were examined and data reduction was achieved (in line with the Miles and Huberman (1994) approach) by identifying and presenting the comments that best represented the overall feedback from the clients.

\section{Findings}

The participants were asked to agree or disagree with the four statements to provide some pattern recognition and then explain their response. The quotations provided were chosen to represent the main views being expressed. Each quotation has an identifier which includes the job title, type of organisation and size of organisation $(1=0-10$ employees, $2=$ 11 - 50 employees, 3 = 51 - 250 employees and 4 = over 250 employees).

Table 3: Four statements with quantitative results

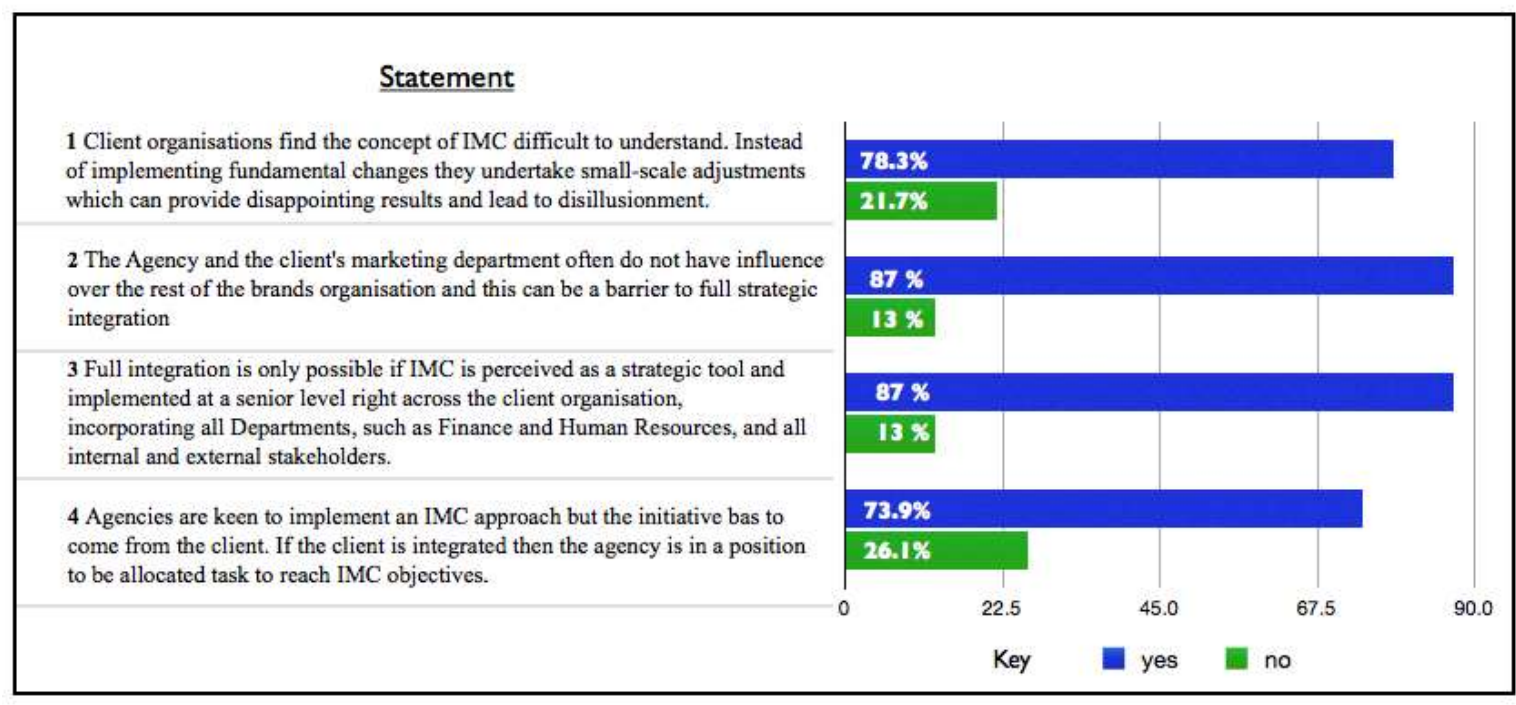

Statement 1: Client organisations find the concept of IMC difficult to understand. Instead of implementing fundamental changes they undertake small-scale adjustments which can provide disappointing results and lead to disillusionment. 
The quantitative results from Statement 1 revealed that most clients supported this statement and considered IMC to be a difficult concept. This does not necessarily mean that they do not understand IMC but indicates that they perceive a lack of knowledge or uncertainty which could make them reluctant to introduce changes in their organisation. The qualitative data explain this reluctance further, as indicated in these comments.

Lack of understanding the full process and benefits can lead to misjudged campaigns and poor results

(Marketing Manager, B2B, Size 3)

This is very much influenced by the level of experience in the organisation....sometimes organisations think they can apply new ways, only to find out that there are cultural, functional, and other barriers that reduce the effects and implementation (Senior Director, Manu, Size 4)

A lot of client organizations don't really know IMC and how to work with it. (Consumer Activation Manager, Manu, Size 4)

From my experience this statement is true, working in a company that comes from a very product/retail focus, and who appear to be incapable of shifting truly towards an integrated way of working.

(Communications Manager, Manu, Size 4)

The comments revealed that participants had experienced the reluctance of organisations to take the big step into full integration because of their lack of understanding not only of the process but also of the benefits of doing so. One participant explained that organisations had to become more marketing orientated overall and it was not just an issue for IMC. The participants refer to barriers identified in the literature e.g. cultural, functional and lack of internal communications. This apprehension is understandable, particularly in today's business climate where short-term and accountable goals are often being set. If the future of a company looks challenging then clients may be more risk-adverse and introduce 
more immediate but less fundamental changes to organisational structures and responsibilities.

Statement 2: The Agency and the client's marketing department often do not have influence over the rest of the brand's organisation and this can be a barrier to full strategic integration.

There was strong support for this statement, with the majority agreeing that the influence of the marketing department over other parts of the organisations is an important issue. The comments chosen illustrate the main issues identified.

In its essence, the statement is true that even marketing departments do not have the influence over their internal stakeholders...especially in organisations in which marketing has been reduced to functionalities and strategic marketing thinking is absent (which, I believe, is true for very many organisations).

(Senior Director, Manu, Size 4)

Often departments within a business work independently, however it is down to the marketing department to drive the strategic direction (with the support of the CEO). (Marketing Executive, Retail, Size 4)

Partly true but even if the formal responsibility and budget ownership is not there, influencing and education can still achieve the integration.

(VP, Manu,Size 4)

Too often in my experience, CEOs, FDs and non-execs think they know best when it comes to marketing strategy. Their thinking on marketing issues is often outdated (from my experience in service-based sectors).

(Comms Director, Not-Profit, Size 2)

In brand-centric organisations this should be easier-marketing is recognised as a key business driver (board role) and integrated in business planning, rather than add-on. 
(Marketing Director, Manu, Size 4)

The participants discussed the importance of being brand-centric and how this approach needed to infiltrate other departments and be a key business driver in order to achieve true integration. However, it was recognised that this approach may be achieved in true brand focused organisations but not in others. Participants explained that many departments worked quite independently and due to lack of strategic thinking, were not included in the marketing agenda. Although C-suite support was not referred to in the statement, its importance came through clearly, with many statements referring to their role. Some respondents explained that if they do not have the support of the CEO or someone at board level then gaining cooperation of other departments can be difficult to achieve. Others comment that there might be CEO support but their knowledge of IMC can be weak or outof-date which is not helpful.

Statement 3: Full integration is only possible if IMC is perceived as a strategic tool and implemented at a senior level right across the client organisation, incorporating all departments, such as Finance and Human Resources, and all internal and external stakeholders.

These results would suggest that the clients are aware of the need to integrate IMC at the strategic level, with the majority of the clients agreeing with the statement. The influence that the marketing department can have over others is again evident in the comments provided.

...But of course this is very difficult to achieve in practice, given that the marketing function is rarely the core department, capable of wielding the influence to drive this approach. (Comms Director, Not-Profit, Size 2)

Does not need to include all departments only relevant ones (Marketing, Product, Brand, to some extent Sales)

(Marketing Director, Manu, Size 4) 
The whole company should live and breathe the same objectives and culture (Marketing Ex, Retail, Size 4)

It is of interest to compare the last two comments as they represent a difference of opinion of the participants with one questioning whether the HR department and Finance needed to be included in this process. This is evidence that some clients still perceive IMC at a brand level compared with corporate or strategic level. However, overall, the clients indicated that they did appreciate the importance of involving the whole organization which suggests that their knowledge of IMC may be stronger than they perceive it to be, as indicated in Statement 1.

Statement 4: Agencies are keen to implement an IMC approach but the initiative has to come from the client. If the client is integrated then the agency is in a position to be allocated tasks to reach IMC objectives.

This statement on the client-agency responsibility for IMC implementation created more disagreement and discussion than the other statements. The majority of the clients stated that it was up to the client to implement IMC. The following statements provide an insight into the perceptions of clients in relation to this issue.

Agencies are not empowered to change client organisations so it has to come from the client.

(Consultant, Financial, Size 3)

IMC cannot just be 'inflicted'...the client company needs to believe in the benefits and ROI of IMC.

(Senior Director, Manu, Size 4)

It's not only about agency issues. The integrated approach has to be implemented all through the clients organisation, working with the internal culture, brands, $R \& D$, products and channels etc.

(Consumer Activation Manager, Manu, Size 4) 
These comments suggest that some clients feel that the implications of IMC go much further than the work of their advertising agencies, with other departments being involved that are outside the remit of the agency and consequently it has to come from within. However, some of the clients were quite vocal in their views stressing that the agency does have a role to play here. Because this is the largest group of clients who disagreed with the statement some of their comments are also interesting to examine.

A good agency won't wait for the client! In my experience when using agencies I go to them because I want their expertise...I want them to look into the business and give added value and that means proposing IMC if required.

(Director, Consultant, Size 1)

There is no reason why the agency could not initiate this way of working.

(VP, Manu, Size 4)

These comments indicate some differences in the relationships that exist between agencies and clients. There is certainly evidence that some agencies are getting more involved with branding issues and producing work for not only external but also internal audiences. One of the participants highlighted the fact that if the agencies are not integrated amongst themselves it makes it more difficult for the client to adopt an integrated approach.

Yes, but I would also challenge agencies to become more integrated themselves. A lot of agencies come from one discipline, and find it difficult to break away from this and to work with an IMC approach.

(Comms manager, Manu, Size 4)

\section{Discussion}

The findings firstly indicate that these UK clients are facing similar challenges and barriers to those identified in the literature from other countries (e.g. Eagle and Kitchen, 2000; Ewing 
et al, 2000). This similarity raises alarm bells when one considers that fifteen years has passed since these studies were reported, and yet little seems to have changed, despite the advancement of IMC understanding in the academic literature during this time. The results highlight three main barriers: a perceived lack of knowledge in the area, the marketing department lacking a strong enough voice within the organisation and agencies not assisting in the implementation of IMC. Each barrier is now discussed in turn, along with practical and theoretical implications.

Firstly, results suggest that clients feel that they do not fully understand IMC or how it should be implemented and consequently are not executing the necessary changes. Although there is evidence that their knowledge is generally in line with practitioners, wavering between brand and strategic levels of operation (Laurie and Mortimer, 2011), they perceive a lack of understanding which is leading to lack of confidence. These findings are in line with empirical studies on clients' views of their IMC knowledge undertaken in New Zealand (Eagle and Kitchen, 2000) and Sweden (Holm, 2006). Such trepidation is understandable. The external landscape is changing rapidly, due mainly to the exponential growth of information technology, and it takes confidence for clients to make strategic decisions in such an environment. The conflict theory of decision-making helps to explain how this high-risk situation has led to lack of progress, due to procrastination, shifting responsibility or deciding to do nothing (Wright et al., 2004). It is therefore imperative that this lack of confidence is addressed. Perhaps this situation is not surprising when we consider that many marketing personnel at higher levels of client organisation may have obtained their marketing qualifications, if any, before IMC was an important part of the syllabus. It is therefore necessary for academics and trade organisations to create relevant training materials, workshops and courses, aimed at not only marketing staff but also top management. The UK Chartered Institute of Marketing (CIM) does have a category entitled 'Integrated Marketing Communications' in their Marketing Excellence Awards which is encouraging (CIM, 2015). A closer look, however, reveals that the awards adopt this tactical definition of IMC; 'This award will recognise the organisation that has demonstrated excellence through the use of multiple channels to meet or exceed campaign objectives' (CIM, 2015). Although it is obviously important to recognise success at the tactical level, the more strategic challenges seem to be overlooked. Ironically, the CIM Marketing Confidence 
Monitor Report (2013) states that 'greater emphasis is now placed on marketing's contribution to strategy, influence on corporate decisions and ability to work across the organization' (p. 4) and yet their training schedule does not seem to reflect that.

The other main finding is the lack of authority or influence that marketing departments have over other sections of the organisation, particularly when there is no integration champion at board level. If full integration can only be achieved with the contribution and cooperation of both internal and external stakeholders, (Luck and Moffatt, 2009) then this lack of involvement of internal audiences in different departments is a significant problem. This is obviously linked to entrenched organisational structures and inflexible lines of authority as identified in the literature (Eagle and Kitchen, 2000). The social exchange theory, as discussed earlier, proposes that when levels of control or authority are low, co-operation can still be achieved if levels of trust are high (Das and Teng, 1998). These findings would suggest that marketing departments may have both low control and low trust across other departments. The influence that marketing departments have over other departments is an area of research in its own right and has gained a lot of attention over recent years due to evidence of a correlation between a strong marketing department and business performance (Auh and Merlo, 2011). Merlo (2011) found a need for more formal training and education of marketing issues with top management in order to increase the legitimacy of marketing and its contribution. However, It is also important that marketing departments consider their own image internally and ensure that they are perceived to be a hub of useful information and that they communicate appropriately to internal and external staff (Verhoef and Leeflang, 2009). Nath and Mahajan (2011) found that the more critical resources the Chief Marketing Officer (CMO) is responsible for, including Sales, the more influence he or she will have at board level, particularly if the marketing experience at board level is generally low. Unfortunately, the CIM report (2013) identifies that two of the main challenges facing marketing professionals today are that CMOs do not have the same credibility as CFOs and that marketing is not understood by other business departments. Such a situation would suggest a need to strengthen clients' skills in terms of internal communications and internal marketing. 
Although the majority of clients acknowledge that it is their responsibility to implement IMC, the role of agencies in this seems to be unclear. The studies by Kitchen et al. (2004, 2008) on the agency viewpoint concludes that agencies can help and encourage with a 'bottom up' approach but it ultimately comes down to the client. It would seem from these results that clients generally agree with that, because of the need to implement IMC across the whole organisation. Presumably if the marketing department is having difficulty communicating consistent messages internally, as indicated earlier, then it is unlikely that the outside agency will be any more successful, unless they have the ear of an influential member of the board, particularly if the agencies themselves are not working together (Ewing, et al., 2000; Child, 2012). A Client/Agency Relationship survey, undertaken by Forbes in September 2014 in the US found that clients are increasingly bringing strategic decisions in-house and perceiving agencies less as partners and more as suppliers (Dan, 2014). Not surprisingly, the agency world may disagree with this. Murphy (2015), the CEO of a large and successful London agency, states that clients are expecting their agencies to become more strategic and to 'anchor their total brand experiences'. He proposes that this will lead to a move back to full-service agencies and a more seamless approach to create strong brand strategies. There also seems to be a growing trend in communications solutions to consider more stakeholders than just the customer, with the internal audience being increasingly recognised by agencies as an important part of the answer (Derrick, 2012). The clear message is that IMC is challenging existing client/agency relationships and ways of working. Integration demands a collaborative and supportive working environment between not only the client and their agencies but also between the agencies themselves. This collaboration is difficult to nurture if clients are bringing more work in house and the contribution of agencies is being questioned.

\section{Limitations and Future Research}

This research provides an insight into the perceptions of a number of UK clients on IMC and the challenges of implementation. It has brought together the views of senior directors and managers across a spectrum of different industries. However, it must be acknowledged that the sample is small and therefore generalisations need to be conducted with care and 
further investigation is needed. The study also only collected the views of one person within each organisation and these views may vary across the same institution. Although the study collected qualitative data, the research instrument prevented an in-depth exploration of issues facing these professionals and was limited to the topics raised by the four statements provided. Indeed, it is planned to explore these initial results further by undertaking more in-depth interviews with some of the participants. Nonetheless, the findings have revealed some interesting insights into the challenges that some clients perceive and opened up areas for future research. The application of the conflict theory and the social exchange theory has been useful in this study to explain some of the findings and if IMC is to be recognised as a strategic approach to marketing communications then change management research, more commonly discussed in the industrial marketing and marketing management literature, needs to be undertaken in the communications context. An example of such a study is Finney and Scherrebeck-Hansen (2010) who developed a model which identified rational, power, political and control influences being experienced by an organisation when undertaking organisational change due to a rebranding exercise, one of the few studies to bring change management and marketing communications disciplines together. This model could be tested in the context of IMC implementation. Case studies of successful integration are also required to not only illustrate the benefits of IMC but also to contribute towards the creation of practical guidelines for organisations to follow. It has been suggested in the findings that the challenges facing the implementation of IMC will vary depending on the type of client organisation and an investigation into the impact of industry type and also organisation structure may throw some light on these differences. Such an investigation would benefit from a more exploratory inductive research approach which is presently lacking for the present literature which is mainly underpinned by surveys. The need for more case studies and in-company research has also been highlighted recently by Kitchen and Burgmann (2015). Lastly, more investigation is needed in to the client/agency relationship and the conditions required for that relationship to support IMC, perhaps by studying specific structures and models to provide the necessary detail.

\section{Conclusion}


It is increasingly acknowledged that the role of the client is key in the implementation of IMC and yet clients have been the unknown quantity in the industry due to lack of research, particularly in the UK. This study goes some way to addressing the balance. The findings indicate that the three main barriers to implementation are that clients do not feel confidence in their level of understanding of IMC, that the marketing department does not have sufficient authority or influence over other parts of the organisation to implement IMC fully, due partly to a lack of representation at board level, and that there is some uncertainty over the role that agencies should play. These results have some similarities with studies conducted in other countries more than fifteen years ago which is an indication that, while our understanding of IMC has developed from an academic perspective during this time, this is not reflected in clients' experiences. It is important for the advertising industry and academics to provide appropriate support in terms of training, examples of good practice and the creation of more practical guidelines to assist clients in convincing internal colleagues of the benefits of IMC, and to have the knowledge and confidence to make the necessary changes. Only then will more companies be able to benefit for the increased business performance that IMC can provide. 


\section{References}

Auh, S. and Merlo, O. (2012), "The power of marketing within the firm: Its contribution to business performance and the effect of power asymmetry", Industrial Marketing Management, Vol. 44, pp. $861-873$.

Barker, R. (2013), "Strategic integrated communication: An alternative perspective of integrated marketing communication?" Communicatio: South African Journal of Communication Theory and Research, Vol. 39 No.1, pp. $102-121$.

Biraghi, S. and Gambetti, R. C. (2013), "Corporate branding: Where are we? A systematic communication-based inquiry", Journal of Marketing Communications, Vol. 21, No. 4, pp. $260-283$.

Child, L, (2012), “Managing integration: The route to integration", Admap, Sept. CIM (2013) "Marketing Confidence Monitor Report" available at: http://www.cim.co.uk (accessed $10^{\text {th }}$ August, 2015)

Christensen, L. T., Firat, A. F. and Trop, S. (2008), "The organisation of integrated communications: toward flexible integration", European Journal of Marketing, Vol. 43, No. 2, pp. $421-452$.

Christensen, L. T., Firat, A. F. and Cornelissen, J. (2009), “New tensions and challenges in integrated communications", Corporate Communications: An international Journal, Vol. 14, No. 2, pp. $207-219$.

Cropanzano, R. And Mitchell, M. S. (2005), "Social Exchange Theory: An Interdisciplinary Review", Journal of Management, Vol. 13, No. 6, pp. $874-900$.

Dan, A. (2014), "What CMOs Are Saying about the Future of Their Relationships with Agencies" available at http://www.forbes.com (accessed $4^{\text {th }}$ August, 2015)

Das, T. K. and Teng, B. (1996), "Between trust and control: developing confidence in partner cooperation in alliances", Academy of Management review, Vol. 23, No. 3, pp. $491-512$. Derrick, S. (2012), "Roundtable Discussion: Plotting the integration journey", available at http://www.Campaignlive.co.uk (accessed on $24^{\text {th }}$ July 2015)

Duncan, T. R. and Everett, S. E. (1993), "Client Perceptions of Integrated Marketing communications", Journal of Advertising Research, Vol. 33, No. 3, pp. 30 - 39.

Duncan, T. R. and Moriarity, S. E. (1998), “A communication-based marketing model for managing relationships", Journal of Marketing, Vol. 62, No. 2, pp. 1 - 13. 
Eagle, L. and Kitchen, P. (2000)," IMC, brand communications, and corporate cultures", European Journal of Marketing, Vol. 34, No. 5/6, pp. 667-686.

Eagle, L., Kitchen, P. J. and Bulmer, S. (2007), “Insights into interpreting Integrated Marketing Communications: A two-nation qualitative comparison", European Journal of Marketing, Vol. 41, No. 7/8, pp. $956-970$.

Easton, G. (2010), “Critical realism in case study research". Industrial Marketing Management, Vol. 39 pp. $118-128$.

Econsultancy (2013) "State of Integrated Marketing: Challenges and Rewards on the Road Ahead" available at http://idma.ie/wp-content/uploads/2014/05/State of Integrated Marketing Report.pdf (accessed on 14th July 2015).

Einwiller, S. A. and Boenigk, M. (2012), “Examining the link between integrated communication management and communication effectiveness in Medium-sized enterprises", Journal of Marketing Communications, Vol. 18, No. 5, pp. 335-361. Ewing, M. T. (2009), "Integrated marketing communications measurement and evaluation", Journal of Marketing Communications, Vol. 15, Issue 2/3, pp. 103 - 117.

Ewing, M. T., De Bussy, N. M. and Caruana, A. (2000), "Perceived agency politics and conflicts of interest as potential barriers to IMC orientation", Journal of Marketing Communications, Vol. 6, Issue 2, pp. 107-119.

Fill, C. (2013), Marketing Communications: brands, experiences and participation, 6th Edition, Financial Times/Prentice Hall.

Holm, O. (2006)," Integrated Marketing Communication: from tactics to strategy", Corporate Communications: An International Journal. Vol. 11, No. 1, pp. 23 - 33. Institute of Practitioners in Advertising (2006), "Magic and Logic: Re-defining sustainable business practices for agencies, marketing and procurement" available from http://www.magicandlogic.co.uk (accessed 10 th June, 2015). Institute of Practitioners in Advertising (2010), "Agencies working better together: How clients can manage multiple communications agencies to achieve better results". Retrieved from http://www.ipa.co.uk (accessed on $2^{\text {nd }}$ July 2015). Johansen, T. S. and Andersen, S. E. (2012), "Co-creating ONE: rethinking integration within communication", Corporate Communications: An International Journal, Vol. 17, No. 3, pp. $272-288$. 
Kerr, G. and Patti, C. (2013), "Strategic IMC: From abstract concept to marketing management tool", Journal of Marketing Communications, Vol. 21 (5), pp. 317 - 339). Kitchen P. J. and Burgmann, I. (2015), “Integrated marketing communication: making it work at a strategic level", Journal of Business Strategy, Vol. 26(4), pp. 34 - 39.

Kitchen, P. J. and Burgmann, I. (2010), “Integrated Marketing Communication”, In Sheth, J. N. and. Malhotra, N. K. (Eds.) Wiley International Encyclopaedia of Marketing, John Wiley and Sons Ltd.

Kitchen, P. J., Kim, I. and Schultz, D. E. (2008), "Integrated Marketing Communications: Practice Leads Theory", Journal of Advertising Research, Vol. 48, No.4, pp. 531 - 546. Kitchen, P. J. and Schultz, D. E. (1999), "A multi-country comparison of the drive for IMC", Journal of Advertising Research, Vol. 39, No.1, pp. 21 - 38.

Kitchen, P. J. and Schultz, D. E. (2009), "IMC: New horizon/false dawn for a marketplace in turmoil?", Journal of Marketing Communications, Vol. 15, No. 2, pp. 197 - 204.

Kitchen, P. J., Schultz, D. E., Kim, I., Han, D, and Li. T. (2004), "Will agencies ever 'get' (or understand) IMC?", European Journal of Marketing, Vol. 38, No. 11/12, pp. 1417 - 1436. Kliatchko, J. (2008), "Revisiting the IMC construct: a revised definition and four pillars", International Journal of Advertising, Vol. 27, No. 1, pp. $113-160$.

Kliatchko, J. and Schultz, D. E. (2014), "Twenty years of IMC: a study of CEO and CMO perspectives in the Asia-Pacific region", International Journal of Advertising, Vol. 33, No. 2, pp. $2-17$.

Laurie S. and Mortimer, K. (2011), "IMC is dead. Long live IMC" Academic vs Practitioners' views, Journal of Marketing Management, Vol. 27, No. 13/14, pp. 1464 - 1478.

Luck, E. and Moffatt, J. (2009), “ IMC - Has anything really changed? A new perspective on an old definition", Journal of Marketing Communications, Vol. 15, No. 5. Pp. $311-325$. Luxton, S., Reid, M. and Mavonda, F. (2014), “Integrated Marketing Communication capability and Brand Performance", Journal of Advertising, Vol. 44, No.1, pp. $37-46$. Madhavaram, S., Badrinarayanan, V. and McDonald, R. E. (2005), “Integrated Marketing communication (IMC) and Brand identity as critical components of brand equity strategy: A conceptual framework and research propositions", Journal of advertising, Vol. 34, No. 4, pp. 69-80.

Maxwell, J. A. (2010), “Using Numbers in Qualitative Research", Qualitative Inquiry, Vol. 16, No. 6, pp. $475-482$. 
Merlo, O. (2011), "The influence of marketing from a power perspective". European Journal of Marketing, Vol. 45, No, 7/8, pp. $1152-1171$.

Mulhern, F. (2009), "Integrated marketing communications: From media channels to digital connectivity", Journal of Marketing Communications, Vol. 15, No. 2/3, pp. 85- 101.

Murphy, J. (2015), "The year ahead for ad agencies" available from

http://www.Campaignlive.co.uk (accessed on $2^{\text {nd }}$ July 2015).

Nath, P. and Mahajan, V. (2011), "Marketing in the C-Suite: A Study of Chief Marketing

Officer Power in Firms' Top Management Teams", Journal of Marketing. Vol. 75, No. 1, pp. $60-77$.

Patti, C. H., Hartley, S. W., van Dessel, M. M. And Baack, D. W. (2015), “Improving integrated marketing communications practices: A comparison of objectives and results", Journal of Marketing Communications, DOI: 10.1080/13527266.2015.1027251

Peters, L. D., Pressey, A. D., Vanharanta, M. and Johnston, W. J. (2013), “Constructivism and critical realism as alternative approaches to the study of business networks: Convergences and divergences in theory and in research practice", Industrial Marketing Management, 42, pp. $336-346$

Pettegrew, L. S. (2000/2001), "If IMC is so good, why isn't it being implemented? Barriers to IMC adoption in Corporate America", Journal of Integrated Communications, pp 29-37. Reinold, T. and Tropp, J. (2012), “Integrated marketing communications: How can we measure its effectiveness", Journal of Marketing Communications, Vol. 18, No. 2, pp. 113 132.

Ryan, A., Tahtinen, J., Vanharanta, M. and Mainela, T. (2012), Putting critical realism to work in the study of business relationship processes, Industrial Marketing Management, 41, pp. $300-311$.

Sayer, A. (1992), Method in social science: A realist approach, $\left(2^{\text {nd }}\right.$ ed), London Routledge, cited in Easton, G. (2010), "Critical realism in case study research". Industrial Marketing Management, 39 pp. $118-128$.

Schultz, D. E. and Kitchen, P. J. (1997), “Integrated Marketing communications in US Advertising Agencies: an exploratory study", Journal of Advertising Research, Vol. 37, No. 5, pp. 7 - 17. 
Swain, W. N. (2004), “Perceptions of IMC after a decade of development: Who's at the wheel and how can we measure success?", Journal of Advertising Research, Vol. 44, No. 1, pp. $46-65$.

Verhoef, P. C. and Leeflang, P. S. H. (2009), “Understanding marketing department's influence within the firm", Journal of Marketing, Vol. 73, March, pp. $14-37$.

Wright, G., van der Heijden, K., Bradfield, R., Burt, G. and Cairns, G. (2004), "The Psychology of Why Organizations Can Be Slow To Adapt and Change", Journal of General Management, Vol. 29, No. 4, pp. $21-36$. 